\title{
Relation between rectal sensation and anal function in normal subjects and patients with faecal incontinence
}

\author{
W M Sun, N W Read, P B Miner
}

\begin{abstract}
The relation between sensory perception of rapid balloon distension of the rectum and the motor responses of the rectum and external and internal anal sphincters in 27 normal subjects and 16 patients with faecal incontinence who had impaired rectal sensation but normal sphincter pressures was studied. In both patients and normal subjects, the onset and duration of rectal sensation correlated closely with the external anal sphincter electrical activity $(r=0.8, p<0.0001)$ and with rectal contraction $(r=0.51, p<0.001)$, but not with internal sphincter relaxation. All normal subjects perceived a rectal sensation within one second of rapid inflation of a rectal balloon with volumes of $20 \mathrm{ml}$ or less air. Six patients did not perceive any rectal sensation until 60 $\mathrm{ml}$ had been introduced, while in the remaining nine patients the sensation was delayed by at least two seconds. Internal sphincter relaxation occurred before the sensation was perceived in three of 27 normal subjects and 11 of 16 patients $(p<0.001)$, and could be associated with anal leakage, which stopped as soon as sensation was perceived. The lowest rectal volumes required to induce anal relaxation, to cause sustained relaxation, or to elicit sensations of a desire to defecate or pain were similar in patients and normal subjects. In conclusion, these results show the close association between rectal sensation and external anal sphincter contraction, and show that faecal incontinence may occur as a result of delayed or absent external anal sphincter contraction when the internal anal sphincter is relaxed.
\end{abstract}

The role of rectal sensation in the prevention of faecal incontinence is poorly understood. Rapid balloon distension of the rectum mimics the rapid propulsion of liquid faeces or gas into the rectum from the more proximal colon and induces an involuntary rectal contraction and relaxation of the internal anal sphincter, a contraction of the external anal sphincter, and a sensation of pressure or pain. ${ }^{\prime}$ It is the external anal sphincter response that is thought to be responsible for maintaining continence. ${ }^{23}$ The evidence suggests that this response is a spinal reflex that is heavily modulated by conscious mechanisms in normal subjects. ${ }^{+}$It is, for example, present in paraplegic patients who have no rectal sensations, ${ }^{56}$ but absent in anaesthetised or sleeping subjects. ${ }^{+}$Thus, in normal subjects, rectal sensation may be closely linked to the external anal sphincter response and hence to continence. This study explores the relation between rectal sensation and the motor responses of the external anal sphincter, internal anal sphincter, and rectum to rapid balloon distension of the rectum in normal subjects and in patients with idiopathic faecal incontinence who have impaired rectal sensation, in order to elucidate the role of rectal sensation in the preservation of faecal continence.

\section{Material and methods}

\section{SUBJECTS}

Twenty seven normal subjects (20 men and seven women) aged 20 to 65 (median age 45 years) were recruited from a population of university staff and students by advertisement. None had any disturbance of defecation or were taking any medication likely to influence anorectal function.

The patient group consisted of 16 patients (nine men and seven women) aged 32 to 65 (median age 48 years) with impaired rectal sensation. They were selected from a total of 160 patients with idiopathic faecal incontinence (aged 19-80 (median=60 years)). Impaired rectal sensation was defined as the failure of the patient to perceive rapid distension of the rectum with volumes of $10 \mathrm{ml}$ or over within two seconds. Clinical examination showed no abnormal perineal descent in the patients with impaired rectal sensation. The remainder of the incontinent patients, who had normal or enhanced rectal sensation, served as a disease control group. Patients with evidence of spinal injury or disease, perineal trauma, or generalised neuropathy were excluded from the study.

\section{ETHICAL CONSIDERATIONS}

All patients and normal subjects gave their written informed consent for the study to be carried out. The protocol was approved by the ethical subcommittee of the Sheffield Area Health Authority in 1984.

\section{METHODS}

With the subjects lying in the left lateral position with the hips flexed $90^{\circ}$, a manometric probe consisting of a polyvinyl 7 lumen tube with an external diameter of $4 \mathrm{~mm}$ and bearing a terminal inflatable balloon constructed from the terminal reservoir of a condom (Durex Dry, LRC Products Ltd, London, UK), was inserted into the rectum. The diameter of the balloon during distension with $10,20,40,60$, and $100 \mathrm{ml}$ of air 
outside the body was $2 \cdot 5,3 \cdot 2,4 \cdot 0,4 \cdot 6$, and $5 \cdot 5$ $\mathrm{cm}$ and these values were almost identical using different balloons $(r=0.99)$. When correctly positioned, the manometric side holes were situated in the anal canal, approximately 0.5 , $1 \cdot 0,1 \cdot 5,2 \cdot 0$, and $2 \cdot 5 \mathrm{~cm}$ from the anal verge, and in the rectum, $4.5 \mathrm{~cm}$ from the anal verge, and the anal pole of the balloon was $8 \mathrm{~cm}$ from the anal margin. The side holes were perfused with water at a rate of $0.4 \mathrm{ml}$ per minute by a low compliance pressurised perfusion system (Mui, PIP 2, Mississauga, Toronto, Canada), and pressures were measured by means of pressure transducers (Statham 2306, Oxnard, California USA) situated in each perfusion line and connected via amplifiers to a multichannel chart recorder (Hewlett Packard, 7758A, Waltham, Mass, USA).

The electrical activity of the sphincter was recorded using a bipolar electrode consisting of two trimel coated wires (diameter $=0.025 \mathrm{~mm}$ ), with their ends bared and hooked and staggered so that they did not come into electrical contact. ${ }^{78}$ These were threaded through a hypodermic needle and the whole assembly was inserted into the superficial part of the external anal sphincter. The needle was subsequently withdrawn, leaving the hooked ends of the wires in situ. The free ends of the wires were bared and attached to an amplifier (Differential type 21C01 URO-DISA, Copenhagen, Denmark), which was connected via an integrator (AC to RMS converter: Anolog Devices AD536, UK) to the chart recorder.

\section{PROTOCOL}

Anorectal motility was recorded under resting conditions for 30 minutes. The subjects were then instructed to contract their anal sphincter as hard as they could for a period of one minute. This was repeated two more times with gaps of at least one minute between the contractions. After a further five minutes' rest, the rectal balloon was rapidly inflated (about $40 \mathrm{ml}$ per second) with serial volumes of $10,20,40,60$, and $100 \mathrm{ml}$ of air. Each inflation was maintained for one minute, the balloon was then deflated and a gap of at least one minute was allowed before the next inflation. Subjects were asked to press the button of a remote event marker when and for as long as they could feel a rectal sensation, and to report the nature of the sensation (wind, desire to defecate, pain).

\section{ANALYSIS OF RECORDS}

The following indices were recorded:

(1) The lowest distending volumes at which the balloon was perceived and sensations of gas in the rectum (wind), a desire to defecate, and pain were experienced.

(2) The lowest distending volumes required to cause rectal contraction (defined as a phasic increase in pressure on the rectal channel of at least $5 \mathrm{~cm}$ water), anal relaxation (defined as a reduction in anal pressure of at least $5 \mathrm{~cm}$ water below the baseline), anal relaxation sustained for the period of rectal distension, and an increase in external anal sphincter activity.
(3) The onset and duration of rectal sensation.

(4) The periods of anal relaxation, phasic increases in rectal pressure, and increased activity of the external anal sphincter.

(5) The maximum basal pressure recorded in the anal canal shortly after insertion of the probe, the minimum basal pressure recorded at the end of 30 minutes, and the maximum squeeze pressure recorded during conscious contraction of the sphincter.

(6) The highest pressure recorded in the anal canal when the rectum was distended (the highest residual anal pressure) with each volume, and the highest anal pressures recorded before and after each distension (preinflation and rebound pressures).

(7) Leakage of perfusion fluid from the anus. This was monitored by the observer and marked on the chart and was defined as an episode of continuous flow of fluid from the anus.

\section{STATISTICAL ANALYSIS}

The relation between the distending volume and the onset and duration of rectal sensation, external anal sphincter activity, internal anal sphincter relaxation, and rectal contraction were determined by Pearson $r$ test. The $\chi^{2}$ test was used to determine the differences between the percentages of normal subjects and patients who experienced rectal sensation or exhibited

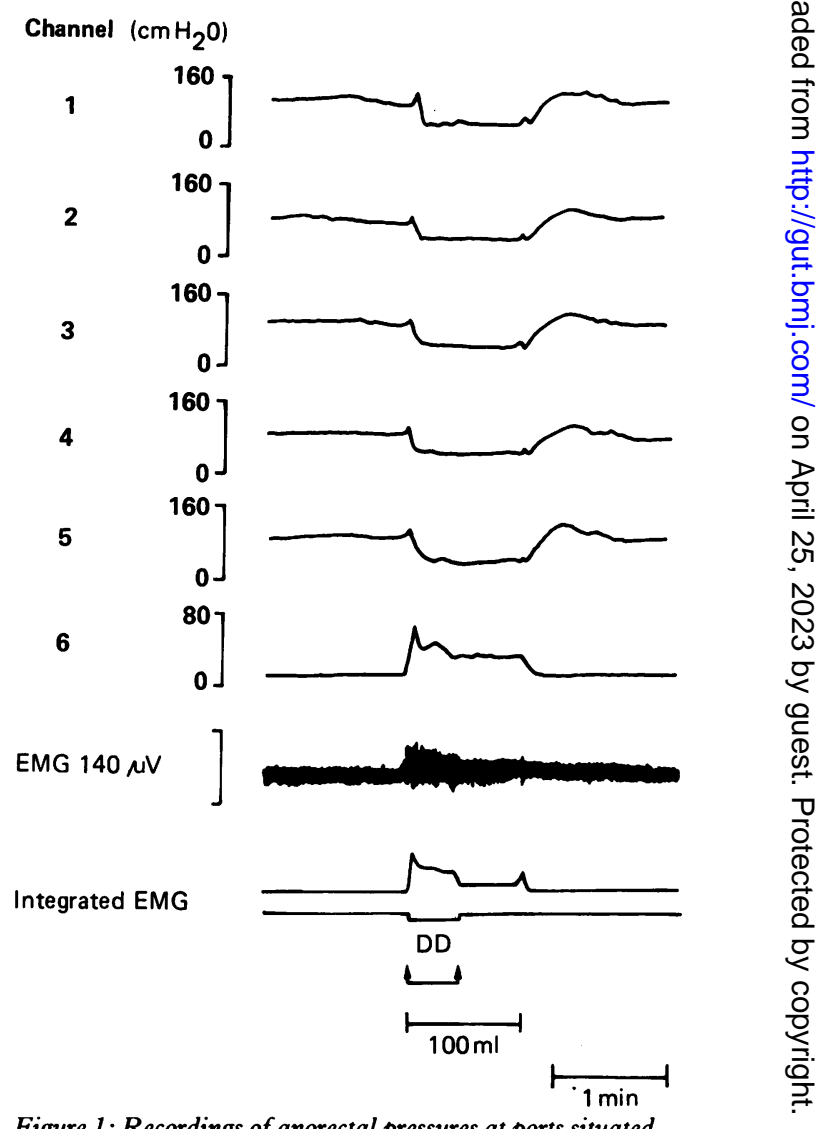

Figure 1: Recordings of anorectal pressures at ports situated $0 \cdot 5,1 \cdot 0,1 \cdot 5,2 \cdot 0,2 \cdot 5$, and $4 \cdot 5 \mathrm{~cm}$ from the anal margin (channels 1 to 6) and the electrical activity of the sphincter complex during distension of a rectal balloon with $100 \mathrm{ml}$ of air. Note that the rectal distension elicits a phasic increase in rectal pressure, anal relaxation, and an increase in external anal sphincter activity. The perception of rectal sensation is also indicated.

$D D=$ desire to defecate $; E M G=$ electromyogram. 
anorectal motor phenomena at different degrees of distension. The statistical significance of the differences in values for anorectal pressures and their duration between normal subjects and patients was assessed using the $F$ test followed by Scheffé's method for multiple comparisons, and differences in rectal sensation were assessed using the Mann-Whitney U test.

\section{Results}

RESPONSES TO RECTAL DISTENSION

Normal subjects. All normal subjects perceived a rectal sensation during rapid distension with 20 $\mathrm{ml}$ air, and all except three (two women and one man) perceived sensation at $10 \mathrm{ml}$ distension. In every subject, distension was perceived within one second of inflating the balloon.

There were close correlations between perception of rectal sensation and the contractile activities of the external anal sphincter and the rectum (Fig 1). Increases in external anal sphincter activity did not take place unless the subject perceived a sensation, the onset of external anal sphincter response always occurred with the onset of rectal sensation, and the length of the external anal sphincter response was strongly correlated $(\mathrm{r}=0.8, \mathrm{p}<0.0001)$ with the duration of sensation (Fig 2). Similarly, rectal sensation was not perceived unless rectal distension elicited rectal contraction. The onset of the rectal contraction always occurred at the same time as rectal sensation and the duration of rectal sensation correlated strongly $(r=0.51, p<0.001)$ with the duration of the rectal contractile response, with the values matching in most instances (Fig 3). Similarly, there was a direct correlation between the duration of the external anal sphincter electrical response and the rectal contractile response to rectal distension $(r=0.5$, $\mathrm{p}<0.01$ ) (see Figs 2 and 3 ).

Inflation of the rectal balloon with volumes of $20 \mathrm{ml}$ and above always caused a reduction in pressure in all anal ports (Fig 1). All except five normal subjects also showed a transient relax-

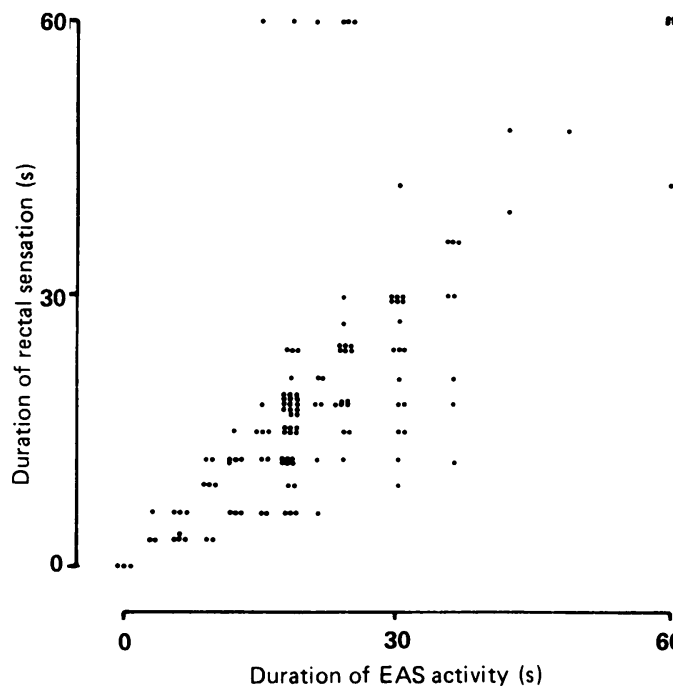

Figure 2: The relation between the duration of rectal sensation and the duration of the increase in electrical activity of the external anal sphincter $(E A S)$ during distension of the rectum of normal subjects with 10 to $100 \mathrm{ml}$ air.

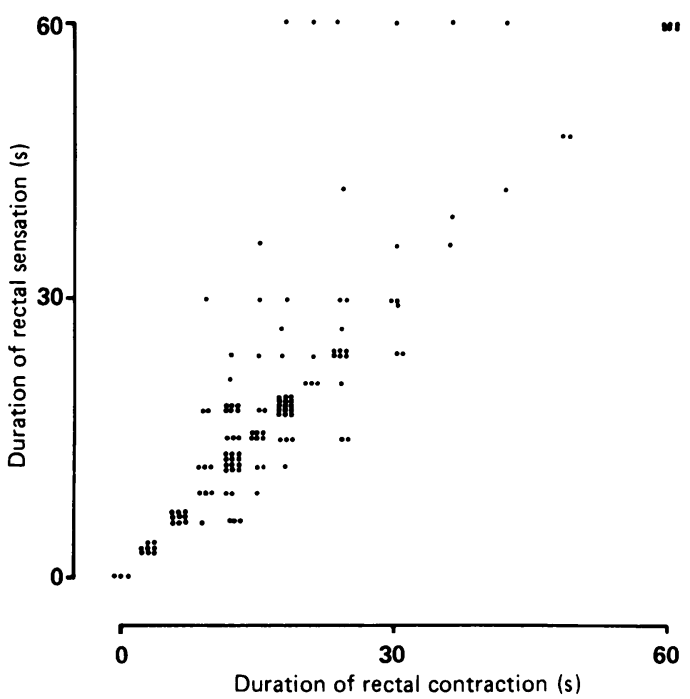

Figure 3: The relation between the duration of rectal sensation and the duration of the rectal contractile activity during distension of the rectum of normal subjects with 10 to $100 \mathrm{ml}$ air.

ation with $10 \mathrm{ml}$ distension (Table I). The anal relaxation increased in amplitude and duration as the distending volume increased, achieving the greatest reduction in pressure at an average distending volume of $60 \mathrm{ml}$ and sustained relaxation at $70 \mathrm{ml}$ (Table I). The relation between rectal sensation and anal relaxation was not as close as it was between rectal sensation and external anal sphincter activity. Although sensation never occurred after anal relaxation had begun, three subjects who did not perceive the balloon at $10 \mathrm{ml}$ distension, showed some anal relaxation at this volume. In contrast, four of the five subjects who did not show anal relaxation with $10 \mathrm{ml}$ distension perceived the balloon at this volume. Normal subjects always perceived a rectal sensation at volumes that were well below those required to cause sustained or the deepest anal relaxation. There was no correlation between the duration of rectal sensation and duration of anal relaxation in any channel. Anal relaxation was always shorter than the duration of rectal sensation, external anal sphincter activity, and rectal responses, all of which were very similar in length.

\section{Patients}

Sixteen of 160 patients $(10 \%)$ referred with faecal incontinence showed impaired rectal sensation during rectal distension. All exhibited a sensory delay of more than two seconds (range, two to 12 seconds) after the onset of the stimulus. Eleven $(69 \%)$ showed no rectal sensation at $10 \mathrm{ml}$ distension $(\mathrm{p}<0.001$, compared with norma subjects), six $(38 \%)$ at 20 and $40 \mathrm{ml}(\mathrm{p}<0.001)$,

TABLE I Lowest rectal distending volumes $(\mathrm{ml})$ required to induce anal relaxation and rectal sensation

\begin{tabular}{llll}
\hline & $\begin{array}{l}\text { Normal } \\
\text { subjects }\end{array}$ & Patients & $p$ \\
\hline Threshold for anal relaxation & $12(1)$ & $11(1)$ & $\mathrm{NS}$ \\
Threshold for sustained relaxation & $73(8)$ & $70(9)$ & $\mathrm{NS}$ \\
Perception of balloon & $11(0 \cdot 6)$ & $26(5)$ & $<0 \cdot 05$ \\
Wind & $30(5)$ & $58(5)$ & $<0 \cdot 05$ \\
Desire to defecate & $65(8)$ & $68(9)$ & NS
\end{tabular}

Data are expressed as mean (SEM). 


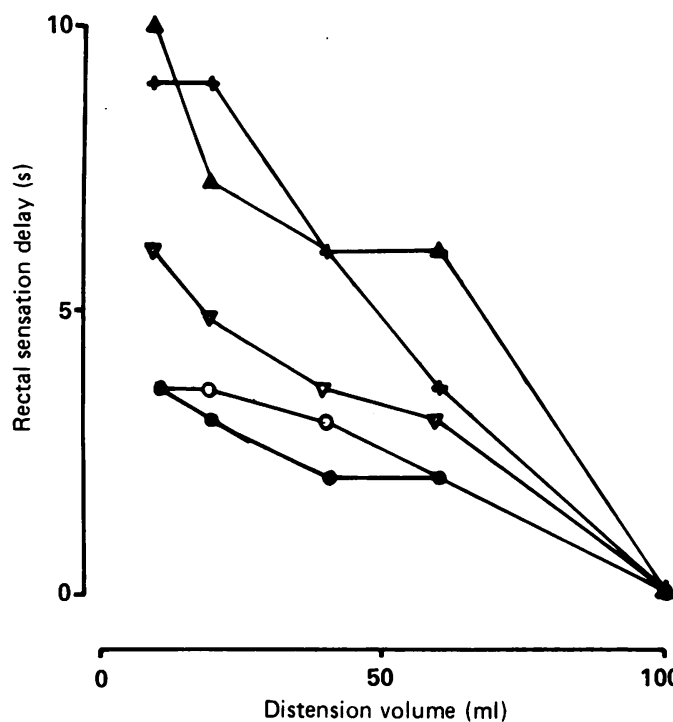

Figure 4: The relation between the delay of rectal sensation and the rectal distending volume in five patients who perceived the rectal sensation at $10 \mathrm{ml}$. All five patients showed reduction and eventual abolition of sensation delay as the rectal distending volume increased.

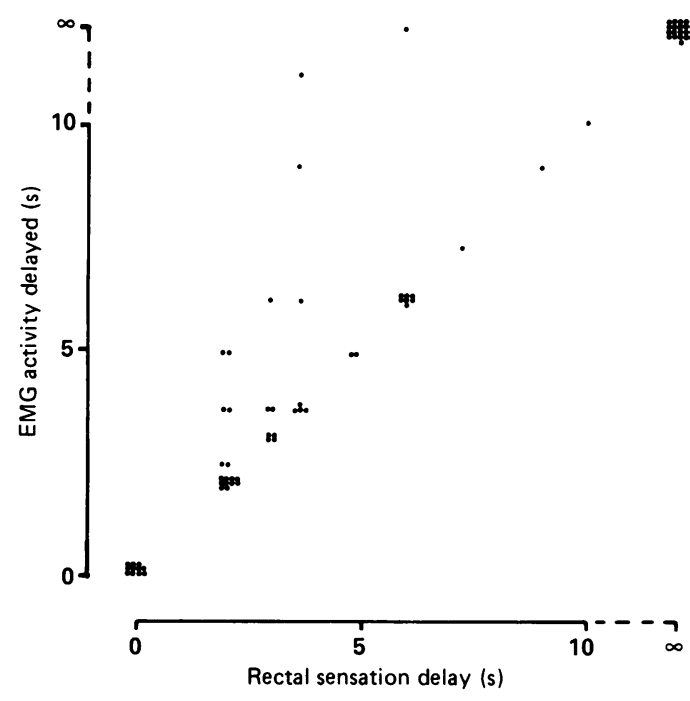

Figure 5: The relation between the length of delay in rectal sensation and the delay in electromyographic (EMG) activity of the external anal sphincter $(E A S)$ in patients during rectal distension with 10 to $100 \mathrm{ml}$ air. $\infty=$ no rectal sensation or no electrical activity of $E A S$ on $x$ and $y$ axes respectively.

sensation was significantly higher in the patients than in normal subjects, the two groups did not differ with regard to the volumes that induced a desire to defecate (Table I), or generated pain $(25 \% v 26 \%$ at $100 \mathrm{ml}$ of distension, $\mathrm{p}>0.05)$.

As with normal subjects, the increase in external anal sphincter activity in response to rectal distension did not occur until the rectal distension was perceived. A delay in sensory perception was always associated with a similar delay in external anal sphincter activity, distending volumes that failed to induce a rectal sensation also failed to cause any external anal sphincter response (Fig 5), and the duration of the sphincter response correlated closely with the duration of the sensation $(r=0.6 ; p<0.001)$. A similar close relation was observed between rectal sensation and rectal contractile activity (duration: $\mathrm{r}=0.54 ; \mathrm{p}<0.01$ ) and between external anal sphincter response and rectal contractile response (duration: $\mathrm{r}=0.5 ; \mathrm{p}<0.01$ ).

Internal anal sphincter relaxation was less closely correlated with rectal sensation or with external anal sphincter activity. Internal anal sphincter relaxation occurred at volumes lower than those required to induce rectal sensation in 11 of 16 patients in the study group compared with three of 27 normal volunteers $(p<0.001)$ and 16 of 144 patients in the disease control group $(\mathrm{p}<0.001)$; and maximum relaxation occurred at volumes below the sensory threshold in two patients in the study group (but in no normal volunteers and in none of the patients' control group). Leakage of fluid from the rectum occurred during rectal distension in five patients, but stopped as soon as they perceived the sensation and the external anal sphincter activity increased (Fig 6).

There were no significant differences between patients and normal subjects in the rectal volumes required to induce anal relaxation and cause sustained anal relaxation (Table I), the duration of anal relaxation from 10 to $100 \mathrm{ml}$ of air, or the anal and rectal pressures recorded during rectal distension.

Although the rectal volume required to induce

\section{ANORECTAL PRESSURES}

It is notable that in this group of incontinent patients, unlike the remainder of the incontinent group, the sphincter pressure shortly after insertion of the probe (maximum basal pressure), the pressure level at steady state (minimum basal pressure), and the maximum squeeze pressure were not significantly different from normal subjects (Table II).

\section{Discussion}

The results of this study show that normal subjects perceive rapid distension of the rectum promptly at volumes of $10 \mathrm{ml}$ and $20 \mathrm{ml}$. These figures, of course, depend on the size and shape of the balloon and the rate of distension; different results may be obtained if the rectum is distended more slowly, and different centres may report different values. The sensation induced by rapid inflation of the balloon with small volumes, was transient, suggesting activation of rapidly adapting receptors. Increasing the volume of distension induced prolonged and more definitive sensations, first wind, next a desire to defecate, and ultimately pain. Rapid inflation of a rectal balloon was used in this study to mimic the propulsion of boluses of gas or liquid into the rectum.

A major observation of this study was the close association between the perception of rectal sensation and the activity of the external anal sphincter in all groups studied. The external anal sphincter responses began at the same time as sensation was perceived, did not occur if there was no sensation, and in most cases lasted approximately the same time as sensation was perceived. These data provide support for the 
Channel $\left(\mathrm{cm} \mathrm{H}_{2} \mathrm{O}\right)$

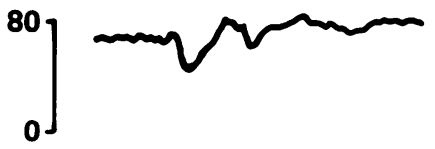

2

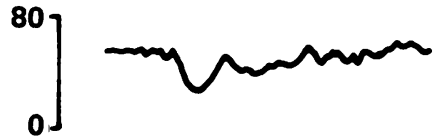

3

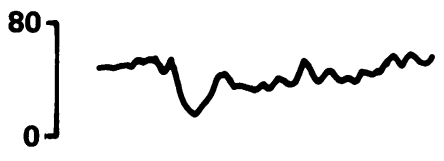

4
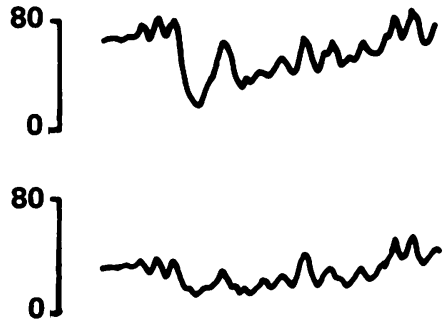

6

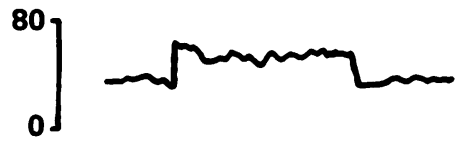

EMG $140 \mu \mathrm{V}$

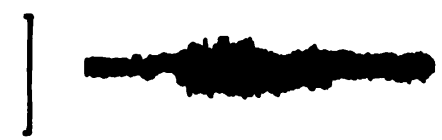

Integrated EMG
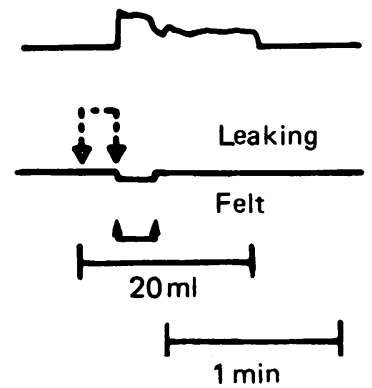

Figure 6: Recordings of anorectal pressures at ports situated $0 \cdot 5,1 \cdot 0,1 \cdot 5,2 \cdot 0,2 \cdot 5$, and $4.5 \mathrm{~cm}$ from the anal margin (channels 1 to 6) and the electromyographic (EMG) activity of the external sphincter during distension of a rectal balloon with $20 \mathrm{ml}$ of air in a patient with impaired rectal sensation. Note that the rectal distension elicits a phasic rectal contraction and internal anal sphincter relaxation. The rectal pressure is higher than the residual anal pressure at the beginning of the distension and leakage occurs. This stops once the subject feel the rectal sensation, which triggers the external anal sphincter activity increasing the anal pressure to a value higher than the rectal pressure.

TABLE II The anal pressure recorded under basal conditions, during maximum conscious squeeze, and during rectal balloon distension with $100 \mathrm{ml}$ of air

\begin{tabular}{lcll}
\hline & $\begin{array}{c}\text { Normal } \\
\text { subjects }\end{array}$ & $\begin{array}{l}\text { Patients with } \\
\text { delayed sensation }\end{array}$ & $\begin{array}{l}\text { Remainder of } \\
\text { incontinent patients }\end{array}$ \\
\hline $\begin{array}{l}\text { Basal } \\
\text { Minimum }\end{array}$ & $51(6)$ & $60(9)$ & $27(3)^{\star}$ \\
$\quad$ Maximum & $94(7)$ & $83(8)$ & $60(4)^{\star}$ \\
$\begin{array}{l}\text { Squeeze } \\
\text { Balloon distension }\end{array}$ & $190(17)$ & $160(27)$ & $105(1)^{\star}$ \\
$\quad \begin{array}{lll}\text { Preinflation } \\
\text { Residual }\end{array}$ & $74(6)$ & $72(9)$ & $31(4)^{\star}$ \\
Rebound & $93(8)$ & $30(6)$ & 25()$^{\star}$ \\
\hline
\end{tabular}

Data are expressed as mean (SEM)

*Significantly different from normal subjects and patients who showed repaired rectal sensation $(p<0 \cdot 05)$ suggestion that the external sphincter response to rectal distension is heavily modulated by conscious mechanisms, ${ }^{4}$ and support an important role for rectal sensation in the preservation of continence when the rectum is rapidly filled with faeces or gas.

To our surprise, we also observed a very close association between rectal sensation and rectal contractile activity, and between rectal pressure activity and external anal sphincter activity. The changes in rectal pressure are not transmitted pressures from the external anal sphincter and associated puborectalis, since the profiles are different and the length of the two events are not identical; so presumably they are caused by contraction of rectal smooth muscle. The close relation between the sensation and both rectal ${ }^{9}$ and external sphincter motor activities suggests the possibility that the evoked rectal contractile activity may be directly responsible for extending and enhancing rectal sensation and hence external anal sphincter activity - a concept compatible with the function of in series tension receptors. ${ }^{10}$ The data would, however, also be compatible with the notion that evoked rectal sensation may lead to rectal contractile activity, or that both effects are induced in parallel by rectal distension.

Rectal sensation was less closely associated with anal relaxation. Most normal subjects perceived sensation before the sphincter started to relax, the rectal volumes required to induce sensation and internal anal sphincter relaxation were often different, and internal anal sphincter relaxation usually lasted for longer than the sensation of rectal distension. Thus, the sensory and external anal sphincter responses to rectal distension do not seem to be directly mediated by relaxation of the sphincter. Nevertheless, the sensory and external anal sphincter responses always occurred at volumes that were much higher than those that caused the deepest or the longest relaxation, and at the highest distending volumes, the external anal sphincter responses were sustained for as long as the internal anal sphincter remained relaxed, maintaining the anal pressure above the pressure in the rectum. These observations illustrate the importance of the external anal sphincter response in preventing incontinence when the rectum is rapidly distended with faeces or gas.

Impaired rectal sensation was found in only $10 \%$ of patients referred with idiopathic faecal incontinence. The observation that these patients had normal sphincter pressures emphasises that impaired sensation may be directly related to incontinence in these patients. Five of these patients leaked fluid from the anus during rectal distension, but the leakage was halted abruptly as soon as the subject perceived sensation and contracted the external anal sphincter.

The results in patients reinforced the close association between rectal sensation and external anal sphincter responses observed in normal subjects. External anal sphincter responses occurred only when subjects perceived sensation, and if the sensory response was delayed the external anal sphincter response was delayed to the same extent. The internal anal sphincter responses were not significantly different from 
those seen in normal volunteers, and thus often occurred at lower volumes than those that induced sensory and external anal sphincter responses. In two patients, maximum internal anal sphincter relaxations occurred at volumes below the sensory threshold. Therefore, the results would support the studies of Wald and Tunuguntla showing that children with meningomyelocele, ${ }^{11}$ patients with diabetic neuropathy, ${ }^{12}$ and some elderly patients with faecal impaction, ${ }^{13}$ whoe have marked impairment of rectal sensation, may suffer from faecal incontinence because they are unable to perceive rectal volumes that can induce profound sphincter relaxation. None of our patients had evidence of neuropathy, however, and their sphincter pressures were within normal range. Moreover, none of our patients had a megarectum, and the rectal volume required to induce anal relaxation and the rectal pressures in patients with impaired sensation were similar to those in normal subjects.

It is important to identify incontinent patients with impaired rectal sensation because the sensory acuity, external sphincter responses, and continence may be restored in many instances by simple retraining techniques." Surgery is often not indicated in these patients because their pressures are normal and there is often no evidence of pelvic floor descent.

I Schuster MM, Hendrix TR, Mendeloff AI. The internal anal sphincter response: menometric studies on its normal sphincter response: menometric studies on its normal physiology, neural pathways and alterat

2 Schuster MM. The riddle of the sphincter. Gastroenterology 1975; 69: 249-62.

3 Read NW, Bartolo DCC, Read MG. Differences in anal function in patients with incontinence to solids and in patients with incontinence to liquids. BrF Surg 1984; 71: 39

4 Whitehead NE, Orr WC, Engel BT, Schuster MM. Externa anal sphincter response to rectal distension: Leared response or reflex. Psychophysiology 1982; 19: 57-72.

5 Melzak J, Porter HH. Studies of the reflex activity of the external sphincter ani in spinal man. Paraplagia 1964; 2: 277-96

6 Freckner B. Function of the anal sphincters in spinal man. Gut 1975; 16: 638-44.

7 Basmajian JV, Stecko G. A new bipolar electrode for electromyography. F Appl Physiol 1962; 17: 849

8 Haynes WV, Read NW. Anorectal activity in man during rectal infusion of saline. A dynamic assessment of the ana continence mechanism. F Physiol 1982; 330: 45-56.

9 Schuster MM. Motor action of rectum and anal sphincters in continence and defecation. In: Handbook of physiolog alimentary canal. Section 6, Vol IV. Washington, DC American Physiology Society, 1968: 2121-46.

10 Iggo $\mathrm{A}$. Tension receptors in the stomach and the urinary bladder. 7 Physiol 1955; 128: 593-607.

11 Wald A. Use of biofeedback in treatment of fecal incontinence in patients with meningomyelocele. Pediatrics 1981; 68 in pa.

12 Wald A, Tunuguntla AK. Anorectal sensation dysfunction in fecal incontinence and diabetes mellitus. $N$ Engl 7 Med 1984: 310: 1282-7.

13 Read NW, Abouzekry L. Why do patients with faecal impaction have faecal incontinence? Gut 1986; 27: 283-7. 